\title{
Efficacy of preoperative percutaneous cholecystostomy in the management of acute cholecystitis according to severity grades
}

\author{
Seong Yeol Kim ${ }^{1}$ and Kyo-Sang Yoo ${ }^{2}$
}

\author{
${ }^{1}$ Department of Internal Medicine, \\ Guil Good Morning Medical Clinic, \\ Seoul; ${ }^{2}$ Division of Gastroenterology \\ and Hepatology, Department \\ of Internal Medicine, Hanyang \\ University Guri Hospital, Guri, Korea
}

Received: July 4, 2016

Revised : October 10, 2016

Accepted: October 23, 2016

\section{Correspondence to}

Kyo-Sang Yoo, M.D.

Division of Gastroenterology and Hepatology, Department of Internal Medicine, Hanyang University Guri Hospital, 153 Gyeongchun-ro, Guri 11923, Korea

Tel: +82-31-560-2229

Fax: +82-31-555-2998

E-mail: kyoo@hanyang.ac.kr
Background/Aims: The aim of this retrospective study was to assess the efficacy of percutaneous cholecystostomy (PC) for patients with acute cholecystitis (AC) according to severity.

Methods: A total of 325 patients who underwent cholecystectomy between January 2008 and October 2010 were enrolled. Patients were classified into three groups based on severity grade according to the Tokyo guidelines for AC: grade I (mild), grade II (moderate), and grade III (severe). These groups were further classified into two subgroups based on whether or not they underwent preoperative PC.

Results: A total of 184 patients were classified into the grade I group (57\%), 135 patients were classified into the grade II group (42\%), and five patients were classified into the grade III group (1\%). In the grade I and II groups, the mean length of hospital stay was significantly shorter in the patients who did not undergo PC than in those who received PC $(10.7 \pm 4.4$ vs. $13.7 \pm 5.8, p<0.001 ; 11.8 \pm 6.5$ vs. $16.9 \pm 12.5, p=0.003$, respectively). The mean length of preoperative hospital stay was significantly shorter in the patients without PC than in those with PC in the grade I and II groups ( $5.8 \pm 3.3$ vs. $8.2 \pm 4.6, p=0.001 ; 6.0 \pm 4.4$ vs. $8.8 \pm 5.2, p=0.002$ ). In addition, the operative time was shorter in patients without PC, especially in the grade I group $(94.6 \pm 36.4$ vs. 107.3 $\pm 33.5, p=0.034)$.

Conclusions: Preoperative PC should be reserved for only selected patients with mild or moderate AC. No significant benefit of preoperative PC was identified with respect to clinical outcome or complications.

Keywords: Treatment outcome; Cholecystostomy; Cholecystitis, acute

\section{INTRODUCTION}

Acute cholecystitis (AC) is a common disease that presents with episodic pain in the epigastrium or right upper quadrant (RUQ) of the abdomen. Following the first successful laparoscopic cholecystectomy (LC) by Mouret in 1987, LC has become the primary choice for managing most benign gallbladder (GB) diseases [1]. Recently, early LC has been recommended for AC based on the results of two randomized studies. Specifically, failure of initial conservative treatment is reported in up to $26 \%$ of cases, and early cholecystectomy has been shown to reduce total hospital stay despite its high conversion rate [2-4].

Percutaneous cholecystostomy (PC) is used as an immediate treatment for the management of AC in elderly or critically ill patients, because emergency cholecystectomy increases the risk of mortality [5]. PC is regard- 
ed as a safe and effective procedure for AC and can be performed with a high degree of technical success $[6,7]$. Elective delayed cholecystectomy after PC may lower the rates of conversion and complication in patients with complicated AC [8-10]. Most studies have reported that $\mathrm{PC}$ is an effective treatment for complicated AC due to empyema, gangrene, perforation, pericholecystic abscess formation, peritonitis, or sepsis [11].

According to the recently issued Tokyo guidelines, PC is recommended for patients with moderate $\mathrm{AC}$ with severe local inflammation and for those with severe AC $[12,13]$. However, only a few studies have addressed the efficacy of PC based on AC severity assessment. As the indications for PC in the setting of AC are still not established, it is difficult to make decisions regarding preoperative PC with subsequent cholecystectomy or early cholecystectomy without PC in clinical practice. The aim of this study was to assess the role of PC in evaluating clinical parameters and outcomes, complications related to $\mathrm{PC}$ and operation, and conversion rates of open cholecystectomy in patients with AC classified according to severity grade.

\section{METHODS}

\section{Study group}

Patients who underwent LC without preoperative LC or preoperative $\mathrm{PC}$ with subsequent elective $\mathrm{LC}$ due to $\mathrm{AC}$ between January 2008 and October 2010 at Hallym University Sacred Heart Hospital were enrolled. Exclusion criteria were biliary drainage procedures other than PC, such as percutaneous transhepatic biliary drainage, nasobiliary drainage, or biliary stent placement for combined common bile duct stones, and hepatobiliary malignancy. All patients were classified into three groups according to the severity grade of the Tokyo guidelines for AC: grade I (mild), grade II (moderate), and grade III (severe) (Table 1) [13]. Each group was further classified into two subgroups of those with or without preoperative PC. This study was approved by the Institutional Review Board of Hallym University Sacred Heart Hospital. The IRB approved a waiver of the requirements to obtain informed consent for this study.

\section{Diagnosis of acute cholecystitis}

The diagnosis of AC was made preoperatively from the characteristic patient's clinical presentation (RUQ abdominal pain, fever, Murphy's sign), laboratory findings (elevated white blood cell [WBC] count or C-reactive protein [CRP] level), and imaging findings (thickened GB wall, pericholecystic fluid collection, enlarged GB) [13]. After establishing a diagnosis of AC, all patients were started on initial medical management comprising nothing by mouth, intravenous fluid, intravenous antibiotics, and analgesics.

\section{Percutaneous cholecystostomy and operation}

PC was performed by a single experienced interventional radiologist under ultrasound and fluoroscopic guidance. The decision to perform PC was made at the physician's discretion based on the patient's clinical condition, response to medical treatment for AC, and surgical risk related to any underlying comorbidities. A 21-gauge Chiba needle (Precision Needle Manufacturing Co., Suwon, Korea) was advanced into the GB through the liver under $1 \%$ lidocaine local anesthesia. After placing a guidewire and dilating the track, an 8.5-Fr pigtail catheter (Multipurpose Drainage Catheter, Sungwon Medical, Cheongju, Korea) was positioned in the GB, and bile was aspirated for culture. Cholangiograms were performed to confirm the correct position of the pigtail catheter within the GB. LC was performed on all patients by two experienced hepatobiliary surgeons.

\section{Data collection}

The following data were collected (1) demographic parameters comprising age, sex, preoperative American Society of Anesthesiologists (ASA) score, and comorbid diseases; (2) clinical parameters: body temperature, presence of abdominal pain, and RUQ tenderness; (3) laboratory findings: WBC count, CRP level, and liver enzymes; (4) imaging findings: GB distension, GB wall thickening, pericholecystic fluid collection, GB stone or sludge, sonographic Murphy's sign, and GB wall disruption; (5) clinical outcome and perioperative complications; and (6) operative time, rates of conversion to open surgery, preoperative and overall hospital stay, and postoperative pathological findings. 
Table 1. TG13 severity grading for acute cholecystitis

\begin{tabular}{|c|c|}
\hline Grade & Criteria \\
\hline $\begin{array}{l}\text { Grade I (mild) acute } \\
\text { cholecystitis }\end{array}$ & $\begin{array}{l}\text { Does not meet the criteria of "Grade III" or "Grade II" acute cholecystitis. Grade I can also } \\
\text { be defined as acute cholecystitis in a healthy patient with no organ dysfunction and mild } \\
\text { inflammatory changes in the gallbladder, making cholecystectomy a safe and low-risk op } \\
\text { erative procedure }\end{array}$ \\
\hline $\begin{array}{l}\text { Grade II (moderate) acute } \\
\text { cholecystitis }\end{array}$ & $\begin{array}{l}\text { Associated with any one of the following conditions: } \\
\text { 1. Elevated white blood cell count }\left(>18,000 / \mathrm{mm}^{3}\right) \\
\text { 2. Palpable tender mass in the right upper abdominal quadrant } \\
\text { 3. Duration of complaints }>72 \text { hours } \\
\text { 4. Marked local inflammation (gangrenous cholecystitis, pericholecystic abscess, } \\
\text { hepatic abscess, biliary peritonitis, emphysematous cholecystitis) }\end{array}$ \\
\hline $\begin{array}{l}\text { Grade III (severe) acute } \\
\text { cholecystitis }\end{array}$ & $\begin{array}{l}\text { Associated with dysfunction in any one of the following organs/systems: } \\
\text { 1. Cardiovascular dysfunction } \\
\text { Hypotension requiring treatment with dopamine } \geq 5 \mu \mathrm{g} / \mathrm{kg} / \mathrm{min} \text { or any dose of } \\
\text { norepinephrine } \\
\text { 2. Neurological dysfunction } \\
\text { Decreased level of consciousness } \\
\text { 3. Respiratory dysfunction } \\
\mathrm{PaO}_{2} / \mathrm{FiO}_{2} \text { ratio }<300 \\
\text { 4. Renal dysfunction } \\
\text { Oliguria, creatinine }>2.0 \mathrm{mg} / \mathrm{dL} \\
\text { 5. Hepatic dysfunction } \\
\text { PT-INR }>1.5 \\
\text { 6. Hematological dysfunction } \\
\text { Platelet count }<100,000 / \mathrm{mm}^{3}\end{array}$ \\
\hline
\end{tabular}

$\overline{\mathrm{PaO}_{2}}$, arterial partial pressure of oxygen; $\mathrm{FiO}_{2}$, fraction of inspired oxygen; PT-INR, prothrombin time-international normalized ratio.

\section{Clinical outcomes}

Clinical outcomes including clinical improvement after PC, operative time, conversion rate to open cholecystectomy, complication rates after surgery, and length of hospital stay were analyzed to assess the efficacy of preoperative PC for the management of AC according to disease severity grade.

\section{Pathological classification}

All preoperative diagnoses were confirmed by histopathological examination of removed specimens. Pathology analysis and cholecystitis grading were conducted by assessing inflammatory cell infiltration, mucosal changes, abscess formation, and wall destruction. AC findings consisted of neutrophil infiltration, edema or ulceration of the mucosal layer, and necrosis. All pathological examinations were reviewed by two experienced pathologists.

\section{Statistical analysis}

Chi-square test was used for univariate analyses to compare baseline characteristics, procedural factors for PC, and clinical outcomes between patients with and without preoperative PC. Multivariate logistic regression analysis was conducted to ascertain the odds ratio of PC related procedural factors.

Additional univariate analyses were performed to compare baseline characteristics, baseline procedural factors, and clinical outcomes among patient groups with or without preoperative PC according to the severity grade of AC.

Statistical comparisons for continuous parameters such as length of hospital stay and operative time among groups were made using independent $t$ tests. A $p<0.05$ was considered statistically significant. All statistical analyses were performed with SPSS version 18.0 (SPSS Inc., Chicago, IL, USA). 
Table 2. Baseline and clinical characteristics of patient groups according to PC

\begin{tabular}{|c|c|c|c|c|}
\hline Characteristic & Overall & Without PC & With PC & $p$ value \\
\hline Number & $325(100)$ & $194(59 \cdot 7)$ & $131(40.3)$ & \\
\hline Age & $57 \cdot 4 \pm 16.3$ & $52.1 \pm 16.17$ & $65.0 \pm 13.19$ & \\
\hline$>65 \mathrm{yr}$ & $123(37.8)$ & $45(23.2)$ & $78(59 \cdot 5)$ & $<0.001$ \\
\hline Sex & & & & 0.357 \\
\hline Male & $181(55 \cdot 7)$ & $104(53 \cdot 6)$ & $77(58.8)$ & \\
\hline Female & $144(44 \cdot 3)$ & $90(46.4)$ & $54(41.2)$ & \\
\hline Previous abdominal surgery & $41(12.6)$ & $16(8.2)$ & $25(19.1)$ & 0.004 \\
\hline Duration of symptom, day & $2.7 \pm 2.2$ & $2.7 \pm 2.3$ & $2.7 \pm 2.0$ & 0.981 \\
\hline ASA score & & & & $<0.001$ \\
\hline $\mathrm{I}$ & $101(31.1)$ & $85(43.8)$ & $16(12.2)$ & \\
\hline II & $178(54.8)$ & $98(50.5)$ & $80(61.1)$ & \\
\hline III & $44(13 \cdot 5)$ & $11(5 \cdot 7)$ & $33(25 \cdot 2)$ & \\
\hline IV & $2(0.6)$ & $\mathrm{o}$ & $2(1.5)$ & \\
\hline WBC, $\times 10^{3}$ cells $/ \mathrm{mm}^{3}$ & $12.5 \pm 8.6$ & $10.9 \pm 9.8$ & $14.9 \pm 5.6$ & $<0.001$ \\
\hline Platelets, $\times 10^{3}$ cells $/ \mathrm{mm}^{3}$ & $251.5 \pm 81.8$ & $252.7 \pm 82.6$ & $245 \cdot 9 \pm 85 \cdot 2$ & 0.473 \\
\hline ALT, IU/L & $72.1 \pm 126.5$ & $82.1 \pm 135 \cdot 3$ & $57.2 \pm 111.1$ & 0.071 \\
\hline $\mathrm{TB}, \mathrm{mg} / \mathrm{dL}$ & $1.5 \pm 1.5$ & $1.5 \pm 1.7$ & $1.4 \pm 1.0$ & 0.645 \\
\hline ALP, IU/L & $236.1 \pm 155 \cdot 3$ & $232.8 \pm 158.1$ & $241.0 \pm 151.4$ & 0.644 \\
\hline $\mathrm{CRP}, \mathrm{mg} / \mathrm{L}$ & $86.2 \pm 99.2$ & $57.7 \pm 80.9$ & $130.7 \pm 108.7$ & \\
\hline Elevated CRP & $172(52.9)$ & $86(44.3)$ & $86(65.6)$ & $<0.001$ \\
\hline
\end{tabular}

Values are presented as number (\%) or mean \pm SD.

PC, percutaneous cholecystostomy; ASA, American Society of Anesthesiologists; WBC, white blood cell; ALT, alanine aminotransferase; TB, total bilirubin; ALP, alkaline phosphatase; CRP, C-reactive protein.

Table 3. Multivariate analysis of preoperative percutaneous cholecystostomy in acute cholecystitis

\begin{tabular}{lcr}
\hline Variable & OR $(95 \%$ CI $)$ & p value \\
\hline Age $(>65 \mathrm{yr})$ & $3.66(1.79-7.49)$ & $<0.001$ \\
Previous abdominal surgery & $3.03(1.17-7.88)$ & 0.023 \\
ASA score & $2.11(1.15-3.87)$ & 0.015 \\
Elevated WBC & $2.33(1.13-4.84)$ & 0.023 \\
High CRP & $2.94(1.25-6.92)$ & 0.013 \\
\hline
\end{tabular}

OR, odds ratio; CI, confidence interval; ASA, American Society of Anesthesiologists; WBC, white blood cell; CRP, C-reactive protein.

\section{RESULTS}

\section{Baseline characteristics and clinical outcomes be- tween patient groups with and without percutane- ous cholecystostomy}

A total of 325 patients were enrolled in this study. The mean patient age was $57.4 \pm 16.3$, and the study population was $55.7 \%$ males (181/325). Among the patients enrolled in this study, 131 (40.3\%) underwent preoperative PC. The demographic data of the two patient groups with or without PC are summarized in Table 2. Advanced age over 65 years, history of abdominal surgery, and higher ASA score were significantly more frequent in the PC group. Males were slightly more predominate in both groups, but the difference was not significant. The mean duration of symptoms to admission was 2.7 days for each group, which did not correlate with the use of PC. WBC count $(p<0.001)$ and CRP level $(p<0.001)$ were significantly higher in the PC group. However, the levels of alanine aminotransferase, alkaline phosphatase, and total bilirubin were not different between groups (Table 2).

According to multivariate analysis, the independent factors that correlated with use of preoperative PC for AC were advanced age over 65 years $(p<0.001)$, a history 
Table 4. Clinical outcomes of patient groups according to PC

\begin{tabular}{lccrr}
\hline Variable & Overall & Without PC & With PC & $p$ value \\
\hline Number & 325 & 194 & 131 & \\
Hospital stay, day & & & & \\
$\quad$ Overall & $12.9 \pm 8.0$ & $11.0 \pm 5.1$ & $15.6 \pm 10.3$ & $<0.001$ \\
Preoperative & $7.0 \pm 4.4$ & $5.9 \pm 3.7$ & $8.5 \pm 5.0$ & $<0.001$ \\
$\quad$ Postoperative & $6.1 \pm 5.8$ & $5.4 \pm 4.2$ & $7.1 \pm 7.4$ & 0.007 \\
Operative time, min & $106.3 \pm 43.1$ & $99.0 \pm 41.3$ & $117.0 \pm 43.6$ & $<0.001$ \\
Conversion rate to open surgery & $13(4.0)$ & $5(2.5)$ & $8(6.1)$ & 0.111 \\
\hline
\end{tabular}

Values are presented as mean \pm SD or number $(\%)$.

PC, percutaneous cholecystostomy.

Table 5. Clinical characteristics of patients according to severity grade of acute cholecystitis

\begin{tabular}{|c|c|c|c|c|c|c|c|c|c|}
\hline \multirow{2}{*}{ Characteristic } & \multicolumn{3}{|c|}{ Grade I $(\mathrm{n}=184)$} & \multicolumn{3}{|c|}{ Grade II $(\mathrm{n}=135)$} & \multicolumn{3}{|c|}{ 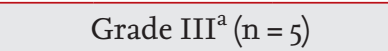 } \\
\hline & $\mathrm{PC}(-)$ & $\mathrm{PC}(+)$ & $p$ value & $\mathrm{PC}(-)$ & $\mathrm{PC}(+)$ & $p$ value & $\mathrm{PC}(-)$ & $\mathrm{PC}(+)$ & $p$ value \\
\hline Number & $133(72.3)$ & $51(27 \cdot 7)$ & & $60(44.4)$ & $75(55 \cdot 6)$ & & 0 & $5(100)$ & \\
\hline Age & $49.6 \pm 14.5$ & $65.6 \pm 11.3$ & $<0.001$ & $57.6 \pm 18.1$ & $65.0 \pm 13.7$ & 0.010 & & $60.2 \pm 22.1$ & NA \\
\hline$>65 \mathrm{yr}$ & $22(16.5)$ & $30(58.8)$ & $<0.001$ & $23(37 \cdot 7)$ & $45(60.0)$ & 0.015 & & 3 & NA \\
\hline Male sex & $72(54.1)$ & $34(66.7)$ & 0.084 & $32(52.5)$ & $40(53 \cdot 3)$ & 1.000 & & $3(60.0)$ & NA \\
\hline ASA & & & $<0.001$ & & & $<0.001$ & & & NA \\
\hline $\mathrm{I}$ & $63(47 \cdot 4)$ & $7(13.7)$ & & $22(36.1)$ & $9(12.0)$ & & - & - & \\
\hline II & $64(48.1)$ & $37(72.5)$ & & $34(55 \cdot 7)$ & $41(54 \cdot 7)$ & & - & $2(40)$ & \\
\hline III & $6(4 \cdot 5)$ & $7(13.7)$ & & $5(8.2)$ & $23(30.7)$ & & - & $3(60)$ & \\
\hline IV & o & o & & o & $2(2.7)$ & & - & - & \\
\hline Comorbidities & $36(27.1)$ & $28(54 \cdot 9)$ & $<0.001$ & $22(36.1)$ & $39(52.0)$ & 0.063 & & 3 & NA \\
\hline $\mathrm{WBC}, \times 10^{3}$ cells $/ \mathrm{mm}^{3}$ & $10.6 \pm 11.4$ & $12.0 \pm 3.8$ & 0.412 & $11.5 \pm 4.8$ & $16.6 \pm 5.7$ & $<0.001$ & & $15 \cdot 5 \pm 7.8$ & NA \\
\hline $\begin{array}{l}\text { Platelets, } \times 10^{3} \\
\text { cells } / \mathrm{mm}^{3}\end{array}$ & $246.6 \pm 79.1$ & $245 \cdot 9 \pm 64.8$ & 0.954 & $265.8 \pm 88.9$ & $250.3 \pm 94.3$ & 0.331 & & $177.8 \pm 111.8$ & NA \\
\hline ALT, IU/L & $79.5 \pm 136.0$ & $52.6 \pm 91.4$ & 0.194 & $87.5 \pm 134.5$ & $62.8 \pm 126.1$ & 0.273 & & $20.0 \pm 8.7$ & NA \\
\hline TB, IU/L & $1.5 \pm 1.7$ & $1.3 \pm 0.9$ & 0.557 & $1.5 \pm 1.7$ & $1.5 \pm 1.0$ & 0.945 & & $1.2 \pm 0.6$ & NA \\
\hline ALP, IU/L & $214.7 \pm 136.4$ & $224.8 \pm 147 \cdot 3$ & 0.662 & $272.1 \pm 192.7$ & $256.3 \pm 157.6$ & 0.600 & & $178.6 \pm 43.4$ & NA \\
\hline CRP, mg/L & $33.2 \pm 51.7$ & $72.7 \pm 69.5$ & 0.003 & $105.5 \pm 103.9$ & $162.9 \pm 113.0$ & 0.007 & & $192.4 \pm 127.5$ & NA \\
\hline
\end{tabular}

Values are presented as number (\%) or mean $\pm \mathrm{SD}$.

PC (-), without percutaneous cholecystostomy; PC (+), with percutaneous cholecystostomy; NA, not applicable; ASA, American Society of Anesthesiologists; WBC, white blood cell; ALT, alanine aminotransferase; TB, total bilirubin; ALP, alkaline phosphatase; CRP, C-reactive protein.

${ }^{\text {a }}$ Statistical analysis for grade III group was not performed because all of the patients underwent preoperative PC.

of abdominal surgery $(p=0.023)$, a higher ASA score $(p$ $=0.015)$, WBC count $(p=0.023)$, and CRP level $(p=0.013)$ (Table 3).

Overall hospital stay (11.0 \pm 5.1 days vs. $15.6 \pm 10.3$ days, $p<0.001)$, preoperative hospital stay $(5.9 \pm 3.7$ days vs. 8.5 \pm 5.0 days, $p<0.001$ ) and postoperative hospital stay ( 5.4 \pm 4.2 days vs. $7.1 \pm 7.4$ days, $p=0.007$ ) were significant- ly longer in patients who underwent PC than in those who did not. In addition, the mean operative time was significantly longer in patients who underwent PC than in those who did not $(99.0 \pm 41.3$ minutes vs. $117.0 \pm 43.6$ minutes, $p<0.001$ ). There was no significant difference in the conversion rate to open cholecystectomy between groups (Table 4). 
Table 6. Clinical outcomes of patients according to severity grade of acute cholecystitis

\begin{tabular}{|c|c|c|c|c|c|c|c|c|c|}
\hline \multirow{2}{*}{ Variable } & \multicolumn{3}{|c|}{ Grade I $(n=184)$} & \multicolumn{3}{|c|}{ Grade II $(n=135)$} & \multicolumn{3}{|c|}{ Grade III $(\mathrm{n}=5)$} \\
\hline & $\mathrm{PC}(-)$ & $\mathrm{PC}(+)$ & $p$ value & $\mathrm{PC}(-)$ & $\mathrm{PC}(+)$ & $p$ value & $\mathrm{PC}(-)$ & $\mathrm{PC}(+)$ & $p$ value \\
\hline Number & $133(72.3)$ & $51(27.7)$ & & $60(44.4)$ & $75(55 \cdot 6)$ & & 0 & $5(100)$ & \\
\hline \multicolumn{10}{|l|}{ Hospital stay } \\
\hline Preoperative & $5.8 \pm 3 \cdot 3$ & $8.2 \pm 4.6$ & 0.001 & $6.0 \pm 4.4$ & $8.8 \pm 5.2$ & 0.002 & - & $7 \cdot 6 \pm 4 \cdot 3$ & NA \\
\hline Postoperative & $4.9 \pm 2.6$ & $5 \cdot 4 \pm 2.4$ & 0.163 & $6.3 \pm 6.4$ & $8.1 \pm 9.4$ & 0.216 & - & $8.6 \pm 4.6$ & NA \\
\hline Overall & $10.7 \pm 4.4$ & $13.7 \pm 5.75$ & $<0.001$ & $11.8 \pm 6.5$ & $16.9 \pm 12.5$ & 0.003 & - & $16.2 \pm 7.6$ & NA \\
\hline Operative time, $\min$ & $94.6 \pm 36.4$ & $107 \cdot 3 \pm 33 \cdot 5$ & 0.034 & $108.5 \pm 49.5$ & $123.9 \pm 48.9$ & 0.074 & - & $114 \pm 35.6$ & NA \\
\hline $\begin{array}{l}\text { Conversion rate to } \\
\text { open surgery }\end{array}$ & $2(1.5)$ & $1(2.0)$ & 1.000 & $3(5.0)$ & $6(8.0)$ & 0.731 & - & $1(20)$ & NA \\
\hline $\begin{array}{l}\text { Postoperative } \\
\text { complications }\end{array}$ & $1(0.8)$ & o & - & $1(1.7)$ & $1(1.3)$ & - & - & 0 & NA \\
\hline
\end{tabular}

Values are presented as number $(\%)$ or mean $\pm \mathrm{SD}$.

PC (-), without percutaneous cholecystostomy; PC (+), with percutaneous cholecystostomy; NA, not applicable.

\section{Comparisons of clinical results in patient groups according to severity grade}

All patients were classified into three groups according to the severity grade of AC; 184 patients (57\%) were classified in the grade I group, 135 patients (42\%) were grade II, and the remaining five patients (1\%) were grade III. Fifty-one patients (27.7\%) from the grade I group, 75 patients $(55.5 \%)$ from the grade II group, and five patients (100\%) from the grade III group underwent preoperative PC. Statistical analysis could not be performed for the grade III group because all five patients in that group received PC before LC.

PC was successful in all patients for whom the procedure was performed, and there were no procedure-related major complications or cases of mortality. All patients except two showed clinical improvement after PC on the basis of resolution of symptoms and signs within 72 hours. One patient in the grade I group underwent early operation due to persistent RUQ pain, and one patient in the grade II group developed a liver abscess.

Clinical parameters and outcomes were analyzed in each of the severity groups. In both the grade I and II groups, patients who underwent PC were significantly older than those who did not $(49.6 \pm 14.5$ years vs. $65.6 \pm$ 11.38 years, $p<0.001 ; 57.6 \pm 18.1$ years vs. $65.0 \pm 13.7$ years, $p=0.01$, respectively). There were significantly more patients older than 65 years who underwent PC in both the grade I and II groups. Additionally, the number of patients with higher ASA score (ASA $\geq$ II) was significantly higher among those who underwent PC. Patients with PC had more comorbid diseases such as hypertension, $\mathrm{DM}$, coronary artery disease, cerebrovascular disease, COPD, and chronic kidney disease. The time interval to PC from admission was less than 24 hours in most patients with PC of any grade.

With respect to laboratory findings, WBC count was significantly higher in patients with PC, especially in the grade II group $(p<0.001)$. CRP level was significantly higher in patients who underwent PC in the grade I and II groups ( $p=0.003$ and $p=0.007$, respectively). After performing PC, mean WBC count and CRP level decreased significantly within 2 to 5 days. There were no significant differences in terms of alanine aminotransferase, alkaline phosphatase, or total bilirubin between groups (Table 5).

The length of overall hospital stay was significantly shorter for patients who did not undergo PC than for those who did in both the grade I and II groups ( $p$ $<0.001$ and $p=0.003$, respectively). The length of preoperative hospital stay was also significantly shorter in patients who did not undergo PC than in those who did in both the grade I and II groups $(p=0.001$ and $p=$ 0.002 , respectively). There were no significant differences among groups in terms of the length of postoperative hospital stay.

In the grade I group, the mean operative time was significantly shorter in patients who did not undergo PC than in those who did undergo PC $(p=0.034)$; however, 
there was no significant difference in mean operative time in the grade II group $(p=0.074)$ (Table 6).

The mean time interval to operation after PC was approximately 1 week for all grades: 7.1 days for the grade I group, 7.8 days for the grade II group, and 6.6 days for the grade III group.

\section{Conversion rate to open surgery and complications}

Conversion to open cholecystectomy was necessary in 13 patients (4\%): three patients in the grade I group, nine patients in the grade II group, and one patient in the grade III group. The differences in the rates of conversion were not significant among groups. All of the patients who required conversion had severe inflammation and adhesions obscuring the plane of dissection and anatomy around Carlot's triangle.

There were no cases of postoperative mortality in any of the three groups. Three patients (1\%) developed postoperative complications, which did not vary significantly between groups. In the grade I group, one patient who did not undergo PC had transient biliary leakage. In the grade II group, one patient who received PC experienced transient biliary leakage, while another patient who did not undergo PC had bleeding at the operation site.

\section{DISCUSSION}

The results of the present study demonstrated that the mean length of hospital stay and operative time in patients with mild and moderate AC were significantly longer for those who underwent preoperative PC, without any difference in the rates of conversion to open surgery or postoperative complications.

According to the Tokyo guidelines proposed in 2013, the severity of AC is classified into three grades: mild (grade I), moderate (grade II), and severe (grade III). PC is recommended for patients with moderate (grade II) disease who do not respond to conservative treatment and those with severe (grade III) disease [12,14]. In clinical practice, the decision to perform PC is usually made based on the patient's poor condition for general anesthesia due to comorbidities or shock, suspected severe $\mathrm{AC}$, or persistent symptoms with impaction of stones in the GB neck $[15,16]$. Because there are no established criteria or guidelines for determining when to perform
PC before LC, a combination of physician's discretion and resource constraints of the hospital may affect the decision to perform PC before LC.

$\mathrm{PC}$ is an effective tool with a high success rate and low morbidity and facilitates safe subsequent surgical treatment, especially for LC [10]. Some surgeons prefer preoperative PC before LC based on the results of previous studies indicating that elective cholecystectomy after PC may lower the conversion and complication rates of patients with complicated AC [8-10,17]. However, several recent studies have reported that PC is associated with increased 30-day mortality, higher odds of death, higher morbidity rates, and higher total costs compared with cholecystectomy [18-20].

The recommendation for PC in cases of severe (grade III) AC is generally accepted in clinical practice. In some institutes, preoperative PC may be performed based on the physician's preference or as an arbitrary indication based on the hospital's policy for delayed surgery rather than according to AC severity grade, especially for moderate or mild AC. In the present study, PC was performed in about $27 \%$ of patients in the mild (grade I) group and $55 \%$ of patients in the moderate (grade II) group. In addition, with respect to moderate AC, the decision to perform PC may depend largely on the patient's age, comorbidities, and ASA score rather than their response to initial medical management.

PC was performed in patients with advanced age over 65 years, comorbidities, and higher ASA score in both mild and moderate AC groups. However, in the moderate AC group, $\mathrm{PC}$ was performed not only for patients who did not respond to conservative management, but also for those who responded to initial medical management. In this case, the decision to perform PC depended largely on the physician's discretion.

According to previous studies, factors such as older age, male sex, prolonged duration of symptoms, and increased inflammatory changes such as WBC and CRP are significant predictors of severe $\mathrm{AC}$ and treatment with PC [21]. However, based on the results of present study, preoperative PC in cases of mild or moderate AC prolonged the total hospital stay and operative time without any additional benefit to clinical outcomes. Although costs were not specifically evaluated in this study, these factors were likely associated with increased total medical expenditures. These results are compara- 
ble with those of previous studies [3,4,22].

Taken together, the results of the present study suggest that early LC be recommended for patients with uncomplicated AC who do not have indications for PC. Thus, PC should be reserved for patients who are not candidates for early LC.

According to subgroup analysis, preoperative and overall hospital stay were significantly longer in patients who underwent PC than in those who did not for both the mild and moderate AC groups. However, there were no significant differences between groups with respect to length of postoperative hospital stay. Rather, patients who underwent PC contributed to the longer preoperative hospital stay in the mild and moderate AC groups. The longer preoperative stay in the PC group may have been due to the time required to perform PC as well as improvement in the condition of patients before surgery. Furthermore, subgroup analysis showed that the mean operative time was significantly longer in patients who underwent PC in both the mild and moderate AC groups. The prolonged operative time in the patients with PC was comparable with previous studies [16,22,23], which may have been due to the presence of dense adhesions, a thickened GB wall, a tendency for bleeding at the site of the operation, and difficulty in identifying anatomical structures during surgery. In contrast, other studies have reported longer operative times in patients who did not undergo PC [9,22].

There were several limitations of the present study. First, this study was retrospective in nature and thus had several innate limitations. In addition, some medical records of clinical presentations may not have been completely documented. Another limitation of this study was that, in each subgroup, physicians decided to preferentially perform PC in patients with old age, comorbidities, and higher ASA score, despite similar severity grades. Further, the individual indications for PC may have varied among the treating physicians. Together, this may have introduced selection bias and influenced the clinical outcomes of the study. This study was also limited by the small number of severe (grade III) patients enrolled, and the fact that all of these patients underwent PC. Therefore, it was not possible to compare outcomes and perform statistical analyses for the grade III group. Lastly, although the present study adopted the revised Tokyo guidelines for severity grading, these guidelines have their own limitations and may not represent all clinical conditions for patients with AC [24].

There are no randomized controlled studies evaluating the outcome of preoperative PC versus early cholecystectomy for AC according to severity grade. Thus, the efficacy of PC should be investigated according to severity of AC. Further accumulation of data is needed to establish a set of unified guidelines regarding the use preoperative PC before LC in patients with AC.

In conclusion, we did not identify a significant benefit of preoperative PC for the management of either mild or moderate AC. With respect to patients with mild and moderate AC, the mean length of hospital stay and operative time were significantly longer for the subgroup of patients who underwent PC. There was no significant difference with respect to clinical outcomes or perioperative morbidities in patients who underwent PC and those who did not. Therefore, preoperative PC should be reserved for only selected patients with mild or moderate AC. More prospective study is needed to establish clear indication of PC in moderate AC to avoid unnecessary PC in clinical practice.

\section{KEY MESSAGE}

1. We did not identify a significant benefit of preoperative percutaneous cholecystostomy for the management of either mild or moderate acute cholecystitis.

2. Percutaneous cholecystostomy should be reserved for only selected patients with mild or moderate acute cholecystitis.

\section{Conflict of interest}

No potential conflict of interest relevant to this article was reported.

\section{REFERENCES}

1. Polychronidis A, Laftsidis P, Bounovas A, Simopoulos C. Twenty years of laparoscopic cholecystectomy: Philippe Mouret: March 17, 1987. JSLS 2008;12:109-111.

2. Gurusamy KS, Samraj K. Early versus delayed laparoscopic cholecystectomy for acute cholecystitis. Cochrane Database Syst Rev 2006;(4):CDoo5440. 
3. Johansson M, Thune A, Blomqvist A, Nelvin L, Lundell L. Management of acute cholecystitis in the laparoscopic era: results of a prospective, randomized clinical trial. J Gastrointest Surg 2003;7:642-645.

4. Papi C, Catarci M, D'Ambrosio L, et al. Timing of cholecystectomy for acute calculous cholecystitis: a meta-analysis. Am J Gastroenterol 2004;99:147-155.

5. Vauthey JN, Lerut J, Martini M, Becker C, Gertsch P, Blumgart LH. Indications and limitations of percutaneous cholecystostomy for acute cholecystitis. Surg Gynecol Obstet 1993;176:49-54.

6. Melin MM, Sarr MG, Bender CE, van Heerden JA. Percutaneous cholecystostomy: a valuable technique in highrisk patients with presumed acute cholecystitis. Br J Surg 1995;82:1274-1277.

7. Patel M, Miedema BW, James MA, Marshall JB. Percutaneous cholecystostomy is an effective treatment for highrisk patients with acute cholecystitis. Am Surg 2000;66:3337.

8. Kuster GG, Domagk D. Laparoscopic cholecystostomy with delayed cholecystectomy as an alternative to conversion to open procedure. Surg Endosc 1996;10:426-428.

9. Kim HO, Son BH, Yoo CH, Shin JH. Impact of delayed laparoscopic cholecystectomy after percutaneous transhepatic gallbladder drainage for patients with complicated acute cholecystitis. Surg Laparosc Endosc Percutan Tech 2009;19:20-24.

10. Paran H, Zissin R, Rosenberg E, Griton I, Kots E, Gutman M. Prospective evaluation of patients with acute cholecystitis treated with percutaneous cholecystostomy and interval laparoscopic cholecystectomy. Int J Surg 2006;4:101-105.

11. Tseng LJ, Tsai CC, Mo LR, et al. Palliative percutaneous transhepatic gallbladder drainage of gallbladder empyema before laparoscopic cholecystectomy. Hepatogastroenterology 2000;47:932-936.

12. Hirota M, Takada T, Kawarada Y, et al. Diagnostic criteria and severity assessment of acute cholecystitis: Tokyo Guidelines. J Hepatobiliary Pancreat Surg 2007;14:78-82.

13. Yokoe M, Takada T, Strasberg SM, et al. TG13 diagnostic criteria and severity grading of acute cholecystitis (with videos). J Hepatobiliary Pancreat Sci 2013;20:35-46.

14. Yamashita Y, Takada T, Kawarada Y, et al. Surgical treatment of patients with acute cholecystitis: Tokyo Guidelines. J Hepatobiliary Pancreat Surg 2007;14:91-97.

15. Han IW, Jang JY, Kang MJ, Lee KB, Lee SE, Kim SW. Early versus delayed laparoscopic cholecystectomy after percutaneous transhepatic gallbladder drainage. J Hepatobiliary Pancreat Sci 2012;19:187-193.

16. Tsumura H, Ichikawa T, Hiyama E, et al. An evaluation of laparoscopic cholecystectomy after selective percutaneous transhepatic gallbladder drainage for acute cholecystitis. Gastrointest Endosc 2004;59:839-844.

17. Chikamori F, Kuniyoshi N, Shibuya S, Takase Y. Early scheduled laparoscopic cholecystectomy following percutaneous transhepatic gallbladder drainage for patients with acute cholecystitis. Surg Endosc 2002;16:1704-1707.

18. Abi-Haidar Y, Sanchez V, Williams SA, Itani KM. Revisiting percutaneous cholecystostomy for acute cholecystitis based on a 10-year experience. Arch Surg 2012;147:416-422.

19. Winbladh A, Gullstrand P, Svanvik J, Sandstrom P. Systematic review of cholecystostomy as a treatment option in acute cholecystitis. HPB (Oxford) 2009;11:183-193.

20. Anderson JE, Chang DC, Talamini MA. A nationwide examination of outcomes of percutaneous cholecystostomy compared with cholecystectomy for acute cholecystitis, 1998-2010. Surg Endosc 2013;27:3406-3411.

21. Schafer M, Krahenbuhl L, Buchler MW. Predictive factors for the type of surgery in acute cholecystitis. Am J Surg 2001;182:291-297.

22. Kim JH, Kim JW, Jeong IH, et al. Surgical outcomes of laparoscopic cholecystectomy for severe acute cholecystitis. J Gastrointest Surg 2008;12:829-835.

23. Kim KH, Sung CK, Park BK, Kim WK, Oh CW, Kim KS. Percutaneous gallbladder drainage for delayed laparoscopic cholecystectomy in patients with acute cholecystitis. Am J Surg 2000;179:111-113.

24. Campanile FC, Catena F, Coccolini F, et al. The need for new "patient-related" guidelines for the treatment of acute cholecystitis. World J Emerg Surg 2011;6:44. 